\title{
TRACTION INJURIES OF THE BRAGHIAL PLEXUS IN ADULTS
}

\author{
Roland Barnes, Glasgow, Scotland
}

From the Department of Orthopaedic Surgery, University of Glasgow

During the recent war many traction injuries of the brachial plexus were treated in the Peripheral Nerve Injury Centres which were established under the aegis of the Medical Research Council of Great Britain. This paper is a review of sixty-three closed injuries of the plexus which were treated in three of these centres. It does not include any postanaesthetic lesions. The mechanism of injury, and the factors influencing the prognosis, are discussed and evidence is cited to support the principle of conservative treatment of the primary nerve lesion.

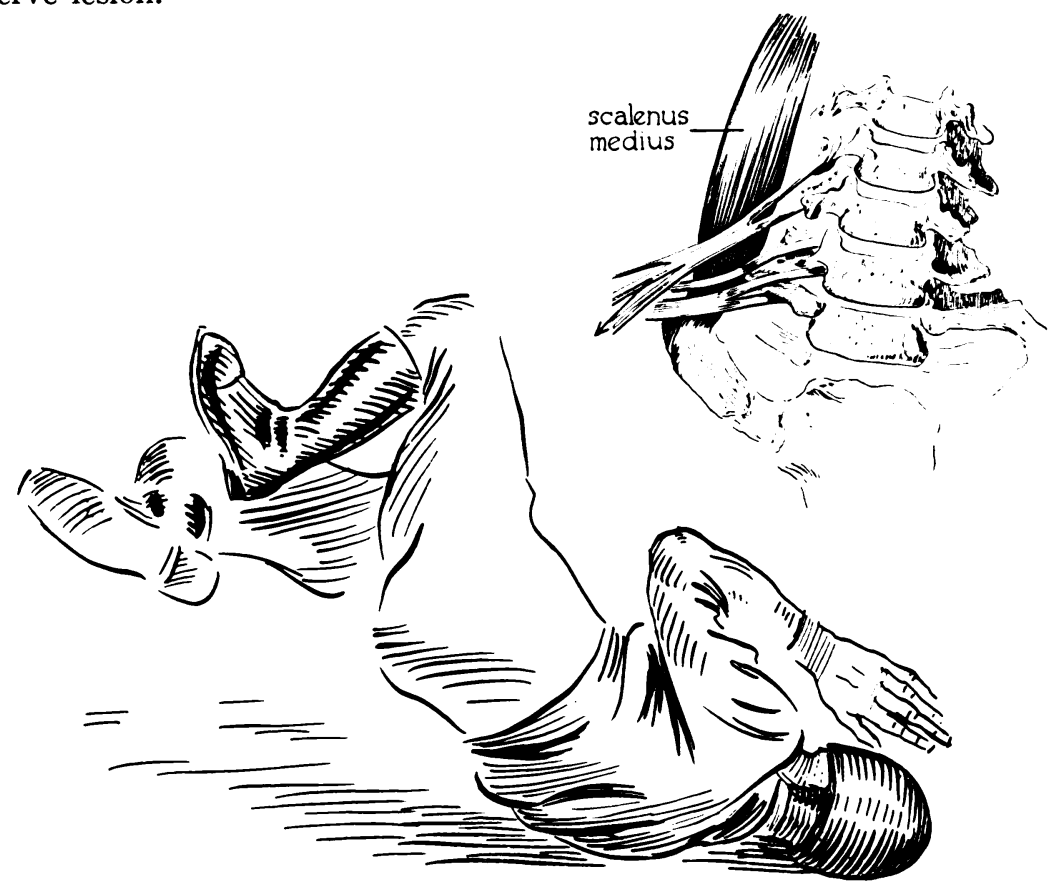

FIG. 1

Mechanism of traction injury of the upper roots of the plexus. With the upper limb by the side, the head and shoulder are forcibly separated. Most stress then falls on the upper roots.

\section{MEGHANISM OF INJURY}

Motor-cycle accidents are responsible for most traction injuries of the plexus. The patient is usually unconscious for some hours, and very often the mechanism of injury is conjectural. It is agreed, however, that in traction injuries the essential factor is forcible separation of the head and shoulder, the position of the upper limb at the moment of impact determining the particular roots of the plexus which will receive the brunt of injury.

The brachial plexus is protected by the scalene muscles and by a strong layer of deep cervical fascia. Violence must be severe enough to tear the fascia, and rupture the scalene muscles, or to avulse the tubercles of the transverse processes from which the muscles arise, before stretching of the nerve roots can occur.

When the shoulder is forcibly depressed with the arm by the side the greatest stress falls on the upper roots, and it is impossible to put the lower roots under tension (Fig. 1). The violence may even cause downward dislocation of the first rib, but the lower roots still escape injury if the limb is by the side. Some additional factor must therefore operate when the lower roots are damaged irreparably. It can be shown by experiment on the cadaver 
that tension is exerted on all roots of the plexus when the abducted limb is forced behind the trunk and the head is thrust towards the opposite side (Fig. 2). The tension on each root varies with the position of the limb: elevation increases tension on the lower roots; adduction increases tension on the upper roots. These observations are in accord with clinical findings, for lesions of the whole plexus may be divided into three types: 1) lesions with permanent paralysis of all muscles of the limb; 2) lesions in which there is early return of voluntary power in muscles innervated by the lower roots, and no recovery in muscles innervated by the upper roots; 3 ) lesions in which there is late return of voluntary power in muscles innervated by the upper roots, and no recovery in muscles innervated by the lower roots.

The lower, or Déjerine-Klumpke, type of paralysis is uncommon in adults. There was

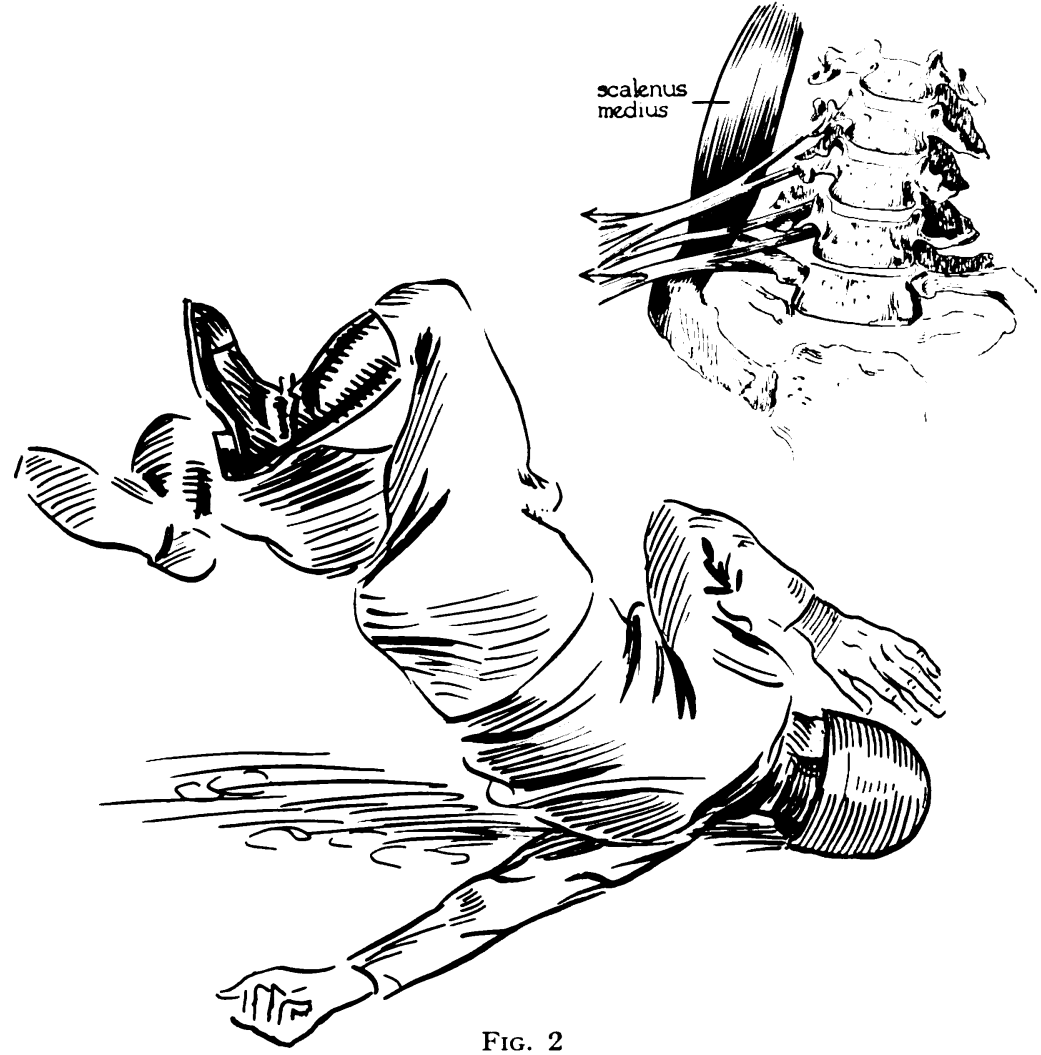

FIG. 2

Mechanism of traction injury of the whole plexus. The abducted upper limb is forced behind the trunk, and the head is thrust towards the opposite side. All roots of the plexus are then under tension.

no pure lesion of C.8 and T.1 roots in this series, but two patients had a lesion of C.7, C.8, and T.1 roots which were not caused by motor-cycle accidents. One patient was blown up by a land mine, and the other was involved in an aeroplane crash; both were unconscious for several hours and it was not possible to elicit details of the mechanism of injury. The probable explanation of the rarity of the Déjerine-Klumpke type of palsy is that in adults violent traction is seldom applied to the fully elevated upper limb, and that the shoulder girdle has not the same mobility in adults as in the new born.

\section{NATURE OF INJURY}

Substantial stretching of nerve roots is possible before actual rupture occurs. Many surgeons believe that rupture of the roots of the brachial plexus is frequent, and this belief has dominated the treatment of traction injuries of the plexus. It is one of the 
favourite arguments advanced in support of early operation. Nevertheless, Stevens (1934) stated that rupture of nerve roots with complete separation of the torn ends was a rare lesion, and this view is supported fully in this series by observations made at the time of operation. Ten severe injuries of the brachial plexus were explored and in only one patient was there complete rupture of the nerve roots.

Moderate stretching of a nerve root causes temporary inhibition of conductivity which affects the motor rather than the sensory fibres. There is no degeneration of the nerve distal to the lesion and complete recovery occurs within two months of injury.

Traction injuries of greater severity cause a degenerative lesion of the axons but no disturbance of the internal architecture of the nerve. Spontaneous recovery of function may be expected, though it is slow because many regenerating axons have to travel long distances before connection with their end-organs is established. With proper treatment, complete recovery may be expected, though not in the intrinsic muscles of the hand. Failure of recovery in these muscles may be explained by irreversible changes occurring in the motor end-plates before the axons re-establish connection with them.

Traction injury of still greater severity causes disruption of the axons and considerable damage to the intraneural blood vessels and connective tissue. Intraneural scarring is then inevitable; recovery is patchy and incomplete, or it may even be prevented altogether.

Very great violence may rupture one or more roots of the plexus. The rupture is never clean cut, and it is always associated with severe scarring of both stumps for some distance on each side of the rupture. For this reason it is impossible to perform satisfactory end-to-end suture of the ruptured nerve after adequate resection of the stumps, and nerve grafting is the only feasible method of restoring continuity.

Most brachial plexus injuries are mixed lesions, for there is wide variation in the traction violence applied to individual nerve roots. All traction injuries are of considerable extent and, in the more severe lesions, several centimetres of the nerve may suffer gross intraneural damage. It is important to appreciate that it is intraneural damage, and not extraneural scarring caused by associated soft tissue injury, which is the barrier to recovery.

\section{GLINIGAL FEATURES}

Traction injuries of the brachial plexus may be divided into four main groups: 1) lesions of C.5 and $6 ; 2$ ) lesions of C.5, 6, and $7 ; 3$ ) lesions of the whole plexus; 4) lesions of C.7, C.8, and T.1. The distribution of anaesthesia and muscular paralysis in each of these groups is too well-known to require description. The muscular branches are not always derived from the same roots of the plexus and for this reason there is some variation in the extent of paralysis in each group. Sometimes the third and fourth cervical roots are involved in the traction injury, in which case the area of anaesthesia extends over the shoulder on to the side of the neck.

Paralysis is always most extensive immediately after injury. Study of these cases has produced no evidence to support the contention of Davis, Martin, and Perret (1947) that "subsequent extensive scar tissue formation tends to impair to various degrees many originally uninjured portions of the plexus, and gives rise to disseminated and incomplete motor and sensory disturbances." This view is still widely held and it is responsible for much futile and even mischievous surgery.

It is impossible by clinical examination to determine the prospects of recovery in degenerative lesions of the nerve roots. The clinical picture of a degenerative lesion of the axons, a lesion with rupture of axons and intraneural scarring, and a complete rupture of the nerve root, are identical. Early operation is often advised in order to discover the exact nature of the lesion but unless the nerve roots are ruptured, which as we have seen is infrequent, there is nothing to be gained. If the nerve is in continuity it is quite impossible by naked-eye examination to give a satisfactory prognosis. 
The lesion is always supraclavicular and the most common situation is in the roots, somewhere between the intervertebral foramina and the point where the roots join to form the three main trunks. Signs pointing to a high lesion of the fifth and sixth roots include paralysis of the diaphragm, rhomboids, and serratus anterior; and in the first thoracic root, Horner's syndrome. In this series, signs of a high lesion were present in seven out of forty traction injuries of the upper roots, and in fifteen out of thirty traction injuries of the first thoracic root.

Pain may be an early and distressing symptom. It is usually most persistent in severe traction lesions of the lower roots of the plexus and it is an unfavourable prognostic sign. Oedema is always a troublesome feature when paralysis is extensive and, unless prevented by prompt and energetic treatment, it causes rapidly increasing stiffness of the joints.

TABLE I

Analysis of Recovery in Lesions of C.5, 6, 7 Roots

\begin{tabular}{|c|c|c|c|c|c|}
\hline \multirow{2}{*}{$\begin{array}{l}\text { Roots } \\
\text { involved }\end{array}$} & \multirow{2}{*}{$\begin{array}{c}\text { Number of } \\
\text { cases }\end{array}$} & \multicolumn{2}{|c|}{ Satisfactory functional recovery } & \multirow{2}{*}{$\begin{array}{l}\text { Incomplete } \\
\text { recovery }\end{array}$} & \multirow{2}{*}{$\begin{array}{c}\text { No } \\
\text { recovery }\end{array}$} \\
\hline & & $\begin{array}{l}\text { Within six } \\
\text { months }\end{array}$ & $\begin{array}{l}\text { Over six } \\
\text { months }\end{array}$ & & \\
\hline $3,4,5$ & 1 & - & 1 & - & - \\
\hline 4,5 & 2 & 1 & 1 & - & - \\
\hline $3,4,5,6$ & 1 & - & - & - & 1 \\
\hline 5,6 & 10 & 4 & 4 & 1 & 1 \\
\hline $3,4,5,6,7$ & 1 & - & 1 & - & - \\
\hline $4,5,6,7$ & 1 & - & - & - & 1 \\
\hline $5,6,7$ & 17 & 4 & 6 & 6 & 1 \\
\hline
\end{tabular}

\section{PROGNOSIS}

Perusal of the surgical literature leaves one with the impression that most traction injuries of the plexus are hopeless surgical problems. So gloomy a view is not supported by this survey, for many lesions of the plexus recovered satisfactorily provided only that meticulous attention was given to the details of conservative treatment.

Non-degenerative lesions of the plexus always recover quickly and completely. They are distinguished easily from degenerative lesions by persistence of normal electrical reactions for longer than eighteen days after injury and by absent, or no more than patchy, sensory loss in the areas normally innervated by the damaged nerve roots (Seddon 1943). In this series, thirteen of the sixty-three injuries of the plexus could be described as non-degenerative lesions and, as one would expect, they were more common when the damage was confined to C.5, 6 nerve roots.

In degenerative lesions the pattern of recovery was fairly constant; lesions of C.5, 6 recovered well, whereas some residual palsy was inevitable in lesions of the whole plexus. The prognosis of lesions of the upper roots of the plexus was not influenced by the level of the lesion, nor by involvement of the third and fourth cervical nerves in addition to the main roots of the plexus (Table I).

Lesions of C.5, 6 nerve roots-There were fourteen patients with lesions of C.5, or C.5, 6 roots (Table I). Eleven patients regained flexion of the elbow, abduction of the shoulder, and external rotation of the shoulder, against gravity and resistance, though not all were capable of sustained effort. Two cases were rated as failures although, in fact, the follow-up

VOL. $31 \mathrm{~B}$, NO. 1, FEBRUARY 1949 
period was not sufficient for final assessment. In one patient there was incomplete recovery in the flexors of the elbow joint. In all cases rated as satisfactory, weak contraction was noted in the paralysed muscles within nine months of injury.

Lesions of C.5, 6, 7 nerve roots-In so far as lesions of C.5, 6, 7 are usually caused by greater violence, the results of conservative treatment are less satisfactory than in lesions of C.5, 6 (Table I). Even so, eleven of the nineteen patients in this group regained extension of the wrist and fingers, flexion of the elbow, and abduction of the shoulder against gravity and some resistance. In six patients there was incomplete recovery of function in the paralysed muscles; and two were failures.

The residual paralysis in the six incomplete recoveries was interesting. Half the patients had residual paralysis of the abductors and external rotators of the shoulder; these injuries of the plexus were apparently caused by forcible depression of the shoulder with the limb by the side. The other three patients had residual paralysis of the extensors of the wrist and fingers, the plexus injury being caused by the abducted limb being forced behind the trunk (Fig. 2).

Illustrative case- $J . D$., aged 19 years, was struck on the left forearm by a heavy piece of stone during an air-raid. The arm was forced backwards and outwards, and there was immediate paralysis and numbness of the whole limb. On admission to hospital, examination revealed a fracture of the left radius, and a traction injury of the C.5, 6, and 7 roots. Within six months of injury there was good recovery in all the paralysed muscles with the exception of those innervated by the seventh cervical nerve root, and in these muscles paralysis was permanent.

Traction injuries of C.5, 6, 7 were usually mixed lesions and the time of reappearance of voluntary power in the paralysed muscles varied considerably. The flexors of the elbow often recovered within two months of injury. Satisfactory recovery was possible in the deltoid even when voluntary contraction was first noticed thirteen months after injury.

Lesions of the whole plexus-There were four non-degenerative lesions of the whole plexus and all recovered completely within six months of injury. In the other twenty-four cases the patient had either permanent paralysis of all muscles of the limb, or incomplete recovery in the muscles innervated by the upper or lower roots of the plexus (Table II).

TABLE II

Analysis of Recovery in Twenty-eight Lesions of the Whole Plexus

\begin{tabular}{|c|c|c|c|c|c|}
\hline \multicolumn{2}{|c|}{ Degree of recovery } & $\begin{array}{l}\text { Number of } \\
\text { cases }\end{array}$ & $\begin{array}{c}\text { Cases with } \\
\text { Horner's } \\
\text { syndrome }\end{array}$ & $\begin{array}{l}\text { Cases with } \\
\text { severe } \\
\text { pain }\end{array}$ & Remarks \\
\hline \multicolumn{2}{|c|}{ Complete recovery } & 4 & - & - & $\begin{array}{l}\text { All were non-degenerative } \\
\text { lesions. Complete recovery } \\
\text { within six months }\end{array}$ \\
\hline \multirow{2}{*}{$\begin{array}{l}\text { Incomplete } \\
\text { recovery }\end{array}$} & $\begin{array}{l}(a) \\
\text { Upper } \\
\text { roots }\end{array}$ & 7 & 6 & 5 & $\begin{array}{l}\text { First sign of recovery in muscles } \\
\text { innervated by C.5, } 6 \text { roots noted } \\
\text { at six to fifteen months from } \\
\text { the date of injury }\end{array}$ \\
\hline & $\begin{array}{l}(b) \\
\text { Lower } \\
\text { roots }\end{array}$ & 10 & 一 & 2 & $\begin{array}{l}\text { Complete recovery of muscles } \\
\text { innervated by C.8, T.1 roots } \\
\text { within two months of injury }\end{array}$ \\
\hline \multicolumn{2}{|c|}{ No recovery } & 7 & 7 & 4 & - \\
\hline
\end{tabular}

Horner's syndrome is always a grave prognostic sign. It indicates irreparable injury of the lower roots and often of the whole plexus. Thirteen of these patients had Horner's syndrome; seven were left with permanent total paralysis of the upper limb; and six regained useful voluntary power in the abductors of the shoulder and flexors of the elbow, but no 
recovery in any muscle of the forearm or hand. The first sign of recovery in the muscles of the shoulder girdle was observed at intervals varying from six to fifteen months.

The ten cases without Horner's syndrome were, with one exception, mixed lesions of the plexus. Sensation was often unimpaired in C.8, T.1 dermatomes. The flexor muscles of the forearm and the intrinsic muscles of the hand recovered completely within a few weeks of injury, leaving the patient with residual paralysis of the muscles innervated by the upper roots of the plexus.

Lesions of G.7, G.8, T.1-In the whole series there were only two lesions of C.7, C.8, T.1 roots. There was no recovery in the one patient who had a Horner's syndrome; the other had a transient lesion of C.7 root, and a degenerative lesion of C.8, T.1 roots, which did not recover.

\section{TREATMENT}

Preventing joint stiffness-In neglected injuries of the brachial plexus, contracture of the joints often causes more disability than muscular paralysis. Oedema is proportionate to the severity of injury, and it is the main cause of joint stiffness; it must be prevented by elevating the limb, usually on an abduction splint. All joints should be put through a full range of movement several times a day. Fractures may prevent full movement of the shoulder joint, but on no account should movements of the wrist and digits be neglected.

Preventing muscle wasting-Continuous stretching of the paralysed muscles is prevented by appropriate splinting. If opposing groups of muscles are paralysed, the mid-position of the joint is chosen. Daily galvanic stimulation will prevent excessive wasting of the paralysed muscles. During the phase of recovery it is essential to re-educate all muscles which are showing feeble voluntary contraction. Prolonged treatment may be necessary, and it is important to allow sufficient time for recovery before considering reconstructive operations. In degenerative lesions of the upper roots, the first sign of recovery may not be observed until at least twelve months after injury.

Relief of pain - In some cases pain is very distressing. It may be relieved by elevating the limb so that the injured roots of the plexus are not under tension. As a rule, pain subsides slowly over a period of several months. Only two operations were performed in this series for persistent pain. One, a patient aged twenty-eight years, complained of severe pain three years after a traction injury of the whole plexus; cervical sympathectomy was performed without success. The other patient, aged fifty years, complained of severe pain four years after irreparable injury of the plexus. In this case the pain was relieved by amputation and exploration of the plexus.

Operative treatment-There is still much difference of opinion as to the indications for operative treatment in traction lesions of the plexus. Jefferson (1930), advocated operation within ten days of the injury, or not at all. His purpose was to determine the extent of the lesion and he believed that primary suture might sometimes be feasible in rare cases where two clean nerve ends were discovered in an accessible position. Recently Davis, Martin, and Perret (1947) have stated " that the best possible results following brachial plexus injuries may be obtained by operation as soon as the acute effects of injury to the soft parts have subsided," and the same authors even advocate exploration of old injuries of the plexus.

We have to consider then: 1) whether early exploration of the plexus is indicated in order to assess the prospects of recovery, or on the off-chance that operative repair of the damaged nerves may be possible; 2) the indications, if any, for late exploration of neglected injuries. The decision presents no difficulty when lesions are confined to the upper three roots of the plexus, for recovery is usually so satisfactory that operative treatment need hardly be considered.

Since only three lesions of the whole plexus were explored within three months of injury there was no direct evidence as to the value of early exploration in assessing the prospects of recovery in these cases. We have seen, however, that it is possible to give a fairly accurate

VOL. $31 \mathrm{~B}$, NO. 1, FEBRUARY 1949 
prognosis on clinical data alone, and it is unlikely that early exploration of the plexus could give more information, apart from the rare occasions when rupture of the roots is disclosed.

It could be argued that the prognosis in lesions of the whole plexus is so bad that it is reasonable to attempt any form of repair of the damaged roots, no matter how unpromising it may seem. Lesions complicated by Horner's syndrome are not now, and probably never will be, amenable to surgery, for the lesion of C.8, T.l roots is so high as to make any type of repair impossible. Lesions without Horner's syndrome are a little more promising. In these the upper roots sustain the brunt of injury, and one can with some confidence look forward to useful recovery in the muscles of the forearm and hand. If the upper trunk of the plexus is attenuated or swollen, there need be no hesitation in resecting the damaged part of the nerve. The main difficulty is that the lesion is not always accessible and that, even if it is, primary suture is impossible after adequate resection. The gap might be bridged by suitable autografts but the number of cases in which grafting is feasible will be few, and it has still to be proved that functional recovery after grafting is as satisfactory as the results of late reconstructive surgery. Seddon (1947) reported one incomplete recovery and two failures in three autogenous cable grafts for traction lesions of C.5, 6 roots. The failures were ascribed to inadequate resection.

Late exploration of the plexus and freeing of nerves from scar tissue may occasionally be justified for the relief of pain which has not responded to conservative treatment. It cannot assist recovery because the chief barrier to regeneration is the endoneural scar.

When the full extent of recovery is known the function of the limb can often be greatly improved by reconstructive surgery. Such operative measures should not be considered earlier than fifteen months from the date of the accident, because recovery in the proximal muscles of the limb has been observed more than one year after injury.

\section{SUMMARY}

1. Sixty-three traction injuries of the brachial plexus in adults are reviewed. Most of the patients were seen at regular intervals for more than three years after injury.

2. The mechanism of injury is described. Forcible separation of the head and shoulder is the essential factor, but the type of lesion is determined by the position of the upper limb at the time of the accident.

3. In traction injuries the main damage is intraneural, and the lesions are of considerable extent. Extraneural scarring is a conspicuous feature of old injuries, but it does not cause any damage to uninjured parts of the plexus.

4. The prognosis of each type of lesion of the plexus is discussed. Satisfactory recovery occurs in most lesions of the upper three roots. Degenerative lesions of the whole plexus never recover completely. Cases with Horner's syndrome always have severe residual paralysis.

5. Conservative treatment is advocated for traction injuries of the plexus and evidence is cited against early or late operations on the plexus. Reconstructive surgical procedures are sometimes indicated.

I am indebted to the staffs of the Peripheral Nerve Injury Centres at Killearn, Oxford, and Winwick for the detailed case records of the traction injuries of the brachial plexus which have formed the basis of this investigation, and especially to $\mathrm{Mr} \mathrm{A}$. R. Parkes, $\mathrm{Mr} \mathrm{H}$. J. Seddon, and $\mathrm{Mr} \mathrm{R}$. Roaf. The illustrations are the work of $\mathrm{Mr}$ G. Donald of the Department of Surgery, Glasgow University.

\section{REFERENCES}

Davis, L., Martin, J., and Perret, G. (1947): Annals of Surgery, 125, 647.

Jefferson, G. (1930): Proceedings of the Royal Society of Medicine. Section of Neurology, 23, 1282.

SEDdon, H. J. (1943): Brain, 66, 237.

Seddon, H. J. (1947): British Journal of Surgery, 35, 151.

Stevens, J. H. (1934): Section on Brachial Plexus Paralysis in the Shoulder by Codman, E. A. Privately printed in Boston, Massachusetts. 